\title{
Ritmos brasileiros no contrabaixo
}

\section{Brazilian rhythms on the double bass}

DOI: $10.46814 /$ lajdv3n3-046

Recebimento dos originais: 01/052021

Aceitação para publicação: 31/06/2021

Felipe Clark Portinho
Doutorando
Instituição de atuação atual UFRJ PPGM
Endereço: Prédio Principal e Prédio de Aulas I, Rua do Passeio, 98 - Centro, Rio de Janeiro - RJ,
20031-170
E-mail. lipeportinho@ gmail.com

\section{RESUMO}

Neste artigo, baseado em pesquisa de campo e entrevistas, traçamos um panorama histórico da transformação e criação dos gêneros musicais brasileiros através do olhar de músicos e musicólogos do Rio de janeiro.

Palavra Chaves: Gêneros brasileiros, música popular brasileira, choro, samba e nossa nova.

\section{ABSTRACT}

In this article, based on field research and interviews, we trace a historical panorama of the transformation and creation of Brazilian musical genres through the eyes of musicians and musicologists from Rio de Janeiro.

Key words: Brazilian genres, Brazilian popular music, choro, samba and nossa nova.

\section{PIXINGUINHA - $1^{\text {AS }}$ BASS LINES}

\subsection{INTRODUÇÃO}

Dos primeiros chorões aparece um gênio descendente dos Iorubás, vindo do bairro do Catumbi e frequentador das casas das Tias na Praça Onze, Alfredo da Rocha Vianna Filho, o Pixinguinha.

Músico, filho de músico e irmão de músicos, foi o grande artista de sua época e das décadas que ainda viriam. Foi a maior das referências para Radamés Gnatalli. Ambos passaram da música ao vivo nas confeitarias e cinemas do Rio de Janeiro para as gravações mecânicas, depois elétricas, para as rádios e por fim para o resto do mundo em poucas décadas.

Flávio Silva (musicólogo): "Pixinguinha era um músico de elite, sabe? Se você for pegar o "Carinhoso", a construção do "Carinhoso" você pode comparar até com a da $5^{a}$ Sinfonia de Beethoven. O inciso e pequeníssimo e que ele vai desenvolvendo."

Luís Filipe de Lima (violonista e escritor): "Bom, já houve quem dissesse que para resumir toda a história da música brasileira basta uma palavra só: Pixinguinha." 
André Tandeta (baterista e professor): "O mercado de trabalho que surgia e que de uma certa maneira estimulava quem queria estudar música de verdade, porque nessa época quando se falava em música era basicamente orquestras, pequenas ou grandes orquestras mas eram orquestras."

Henrique Cazes (cavaquinista e professor): "Então o regional vai oferecer aos violonistas e aos cavaquinistas, e depois também aos percussionistas populares, as primeiras oportunidades de trabalho. Isso vai fazer toda a diferença. Num instrumento como o cavaquinho se não tivesse tido essa oportunidade a gente estaria aqui mais ou menos como o cavaquinho está lá em Portugal."

Luís Filipe de Lima: "E a história do Pixinguinha também claro se confunde tanto com a história do choro quanto com a história do samba e a história da marchinha de carnaval, três gêneros que nasceram no Rio de Janeiro. Uma figura como a do Pixinguinha teve aulas de harmonia $e$ orquestração com o professor Paulo Silva. Uma vez Paulo Silva deu um entrevista em que ele dizia: olha o Pixinguinha é uma figura que me impressiona, pois quando ele era meu aluno tudo o que eu dizia para ele não fazer ele fazia, mas dava certo ."

Flávio Silva: "E o Vicente Salles, um pesquisador que morreu a pouco tempo, figura fantástica do Pará, encontrou um samba carnavalesco em Belém (do Pará) de 1906. Partitura muito fina da editora de Étori Bosel, um italiano."

Henrique Cazes: "É impressionante as gravações de um grupo de choro de Porto Alegre, o Terror dos Facões, de 1913.”

Flávio Silva: “A Casa Electra, gravadora Electra de Porto Alegre, que começou a gravar em 1913, gravou uns 20 discos rotulados como samba entre 1914 e 1916. A expressão Samba Carnavalesco que parece ter sido inventada pelo Donga - Ernesto Joaquim Maria dos Santos (Rio 1890 - 1974) - já aparece em rótulos de disco antes. O samba passou a ser designado como música de sucesso, virou sinônimo de música de sucesso. Então não é dizer que o samba nasceu como o Pelo Telefone, não. Primeiro que não era a primeira gravação, depois que não era samba, eram gravações muito mais de maxixe do que de samba, né? E depois que o samba como a gente conhece só se constitui mesmo depois da década de 20 ."

André Tandeta: "Eram na verdade maxixes."

Henrique Cazes: "Esse núcleo, e particularmente o núcleo ligado ao Pixinguinha e ligado aos frequentadores das Casas das Tias Baianas, participou daquilo do que foi considerado a fundação do samba, marcado com o lançamento do Pelo Telefone, que se transforma num sucesso, uma música que era na verdade uma coleção de refrões."

Flávio Silva: "com o sucesso de Pelo O telefone, um sucesso, cada vez mais se passou a usar a palavra samba. Mas o Pelo telefone mesmo foi um sucesso efêmero. Em 1914 surgiu a Cabocla de Caxangá, a 
Cabocla de Caxangá do Catudo e João Pernambuco, foi cantadíssima em 14, 15, 16, 17 e em 18 a Cabocla foi mais cantada do que o Pelo o Telefone."

Henrique Cazes: "É lançado o Pelo Telefone e a partir dali vai começar o samba, e o samba vai ter um aspecto importantíssimo de ter, desde o primeiro momento, de ter no choro o seu "celeiro de mão de obra" no campo da harmonia."

Flávio Silva: "o Mozart de Araújo mostrou me um artigo do J.F.G. onde dizia que na letra do Pelo Telefone havia um equívoco, a roleta da Carioca que dizia ter sido instalada em 1916 na verdade foi no dia dois de maio de 1913, isso desmontou todo o meu trabalho."

André Tandeta: "Eu fico ouvindo, me parece que no samba tipo Donga e João da Baiana tinha uma percussãozinha assim que não tinha muito importância."

Luís Filipe de Lima: “percussão apareceu um pouquinho depois, nos estúdio sobre tudo."

Flávio Silva: "percussão é raríssima a menção de instrumentos de percussão."

Henrique Cazes: "o choro SEM percussão. As gravações de choro tem três formatos no princípio das gravações no Brasil: um formato com um violão, um cavaquinho e um instrumento solista, o trio. Um outro formato só com sopros, com três ou quatro sopros e sem base. E um terceiro formato com banda de música."

Flávio Silva: "eu nunca vi menção à um grupo formado só de flauta, cavaquinho e violão. Cada grupo era formado com o que tinha por perto."

André "Boxexa” Santos (baterista e professor): "eu acho que faz muita diferença tanto na forma de tocar quanto na acentuação, na dinâmica, no volume de som usado era a formação instrumental. Você tem o trio original formado de flauta, cavaquinho e violão ou outras formações e em outro momento você tem o acordeon tocando e, enfim, não tinha a percussão, mais uma vez eu acho que o grande elo disso tudo era a banda de música."

Flávio Silva: “inclusive a Escola de Samba colocou o samba para andar. Inventaram o surdo, o Bide - Alcebíades Maia Barcelos (Niterói 1902 - Rio 1975) - que inventou o Surdo, pois precisaram de um tambor mais grave para acentuar a marcação do rítmo (no segundo tempo) então o Bide bolou lá o Surdo. Tudo isso foi uma decorrência do aumento do número de figurantes na Escola de Samba. Nesse sentido o samba mesmo era feito para ficar parado no mesmo lugar, não era feito em desfile. Isso era muito mais das tradições de desfile, dos Cucumbis, dos Afoxés e dos Ranchos. A Escola de Samba herda isso tudo e ela vai surgir muito num movimento que é quase de emancipação ou de presença maior dessas classes baixas, vamos dizer. Numa época que os desfiles de Rancho vão desaparecer, porque os desfiles de rancho eram mesmo de classe média. A descrição que o J.F.G dá disso é fantástica no livro, Ameno Resedá, o Rancho que foi Escola. Eram orquestras mesmo! E essas orquestras eram basicamente de sopros e cordas, os Ranchos. Então a Escola de Samba não vai herdar 
somente as coisas que vieram da Bahia, também vai herdar um pouco duma estrutura que vem dos Ranchos e até mesmo das grandes sociedades que eram imitações do s Carnavais Venezianos. Aquilo foi uma criação dos sambistas que pegou aquilo tudo e fez uma salada, e botou o samba pra andar!" Henrique Cazes: "nesse momento quando o samba está se tornando aquilo que ele seria a partir da década de 1930, a grande locomotiva da música popular no Brasil, principalmente a partir do sucesso da Carmem Miranda. O sucesso da Carmem Miranda e falado pelo Ruy Castro, o biógrafo da Carmem, era uma coisa! A Carmem Miranda quando estourou, no começo da década de 1930, os discos dela vendiam dez vezes a quantidade de vezes que o segundo lugar vendia, que era o Francisco Alves. Então a Carmem Miranda praticamente redimensionou a indústria fonográfica no Brasil. Em função da Carmem Miranda muitas oportunidades surgiram: gravadoras, conjuntos, cantoras que foram lançadas "aos borbotões" nos anos 30. Tudo isso aconteceu a partir do fortalecimento do samba. E o personagem principal na estruturação do samba e nas gravações de samba que acontecem principalmente a partir do momento em que passa se do processo de gravação mecânica para o de gravação elétrica, em torno de 1927/28. Quatro empresas internacionais vem se somar à Odeon: A Brunswick, que teve uma vida efêmera, e outras três que ficam: Columbia, a Parlophone e a RCA Victor. Então é uma oportunidade! Surge um leque de oportunidades e quem é o cara que está aparelhado para "vestir" esse samba? É o Pixinguinha!"

Flávio Silva: "você tinha o Sousaphone na música popular, Ophicleide e Sousaphone, instrumentos precursores de tuba, sei lá o que..."

Henrique Cazes: "sim, o choro usou lá no passado o Ophicleide, uma espécie de Ornitorrinco dos instrumentos de sopro. Que era um tubo de metal vertical, um bocal compatível como o trombone ou bombardino e o chaveamento de saxofone, ou seja: uma coisa muito estranha. Mas era um instrumento que se adaptava a tocar como os violões e como cavaquinho. Era um instrumento com uma sonoridade menor, não era um instrumento de grande impacto para tocar em orquestra e que foi muito utilizado. Sendo que o maior de todos foi o professor do Pixinguinha, o Irineu de Almeida, que tem gravações formidáveis tocando com o Pixinguinha, o Pixinguinha com 13 ou 14 anos solando na flauta, tocando muito na flauta e ele tocando muito bem."

Podemos dizer que o contrabaixo no choro e no samba começa exatamente aqui NESSA foto de 1912! Já temos algumas linhas de contraponto para outros instrumentos graves mais portáteis, mas assim como a prova do aparecimento do violão de sete cordas fica registrada pela primeira vez na história com Otávio Vianna, o China, irmão mais velho de Pixinguinha na foto de 1910 - que veremos em seguida - nessa, está o músico Bonfiglio de Oliveira no contrabaixo junto ao Pixinguinha na flauta, 
com apenas 15 anos, Otávio Silva ao piano e Pádua Oliveira ao violino, na choperia La Concha, na Rua da Carioca.

Porém o violão de sete cordas vai ter muito mais registros até o começo das orquestrações usadas nas rádios pouco mais de uma década a partir desse ponto.

Luís Filipe de Lima: "o violão de sete cordas ele aparece, a gente imagina, que na virada do século XIX para o século XX, e dois músicos que a gente sabe que mexiam com esse instrumento: o China, Otávio Vianna, irmão dez anos mais velho do que o Pixinguinha, e o Tute, Artur Nascimento, que tinha a mesma idade que o China praticamente. O China morreu moço, morreu com 20 e poucos anos nos anos 1930 e o Tute morreu na década de 1950. Durante décadas a gente só ouvia mesmo falar do Tute, tinha gravações e tal desde a fase mecânica, tem alguma coisa dele com o Sete Cordas por volta já de 1904, registros desse violão que a gente identifica porque sabe que tem um bordão mais grave que o mi grave do violão de seis cordas.

A gente não sabe muito bem definir a origem do violão de sete cordas brasileiro. A gente sabe que existe um violão de sete cordas que era usado na música popular mexicana no século XVIII, mas no século XIX já teria caído em desuso e tem o violão de sete cordas russo que era muito usado sobretudo na primeira metade do século XIX, ele era um violão solista, esse violão de sete cordas russo com a afinação muito peculiar, um acorde de sol maior, do grave para o agudo você tem: ré, sol, si, ré, sol, si e ré. Dizem que esse violão russo chegou aqui no Rio de Janeiro no final do século XIX trazido por ciganos russos. O pessoal, a turma do Pixinguinha, que frequentava as festas da Casa da Tia Ciata e das outras Tias Baianas, na Cidade Nova (Estácio), teriam proximidade com esses ciganos e essa é uma hipótese muito provável, mas até hoje não foi documentada, carece de documentação. Eu sou um pouco culpado de ter divulgado essa hipótese que me foi passada por seu Arthur de Oliveira, que foi o biógrafo tanto do Pixinguinha quanto do Cartola. O pixinguinha fala um pouco sobre os ciganos do Catumbi, que foi o bairro onde ele próprio foi criado, o pai os irmãos, etc. Morava todo mundo ali . E ele fala fala sobre os ciganos do Catumbi, mas não faz, nenhuma referência ao violão de sete cordas. Alguém pode muito bem ter pensado: caramba se eu tiver um violão com uma corda grave a mais vai me facilitar na hora de executar as baixarias, frasear na região grave do instrumento, eu vou ganhar algumas notas.

Claro, a história do violão de sete cordas ganha muito mais visibilidade como Dino, o Dino sete cordas - Horondino José da Silva (Rio 1918 - 2006) - tocava seis cordas desde 1935, quando ele começou a tocar no regional do Benedito Lacerda, mas ele só foi tocar o violão de sete entre 1952 e 53. Ele contava que pensava em tocar violão de sete cordas, mas por respeito ao Tute, só quando o Tute faleceu que ele tomou coragem e mandou fazer um violão de sete cordas." 
Henrique Cazes: "e muitas vezes a gravação não tem piano, tem violão cavaquinho ou banjo, percussão e tudo mais. Nada disso estava escrito, ele (Pixinguinha) trabalhava com músicos de base que não liam.

Luís Filipe de Lima: "Pixinguinha! Um gênio da música brasileira: gênio como instrumentista, como arranjador, como compositor..."

Henrique Cazes: "se você pensar que o cara tocava aquele negócio reto assim ... que não fazia muito, seria relativamente fácil dar certo, mas o incrível é que ele conseguia com esses músicos fazer coisas sofisticadas de utilização de convenções de ritmo, de mudanças de andamento, modulações, breques, breques com tamanhos diferentes para cada momento do arranjo. E os caras conseguiam memorizar isso e aprender."

Luís Filipe de Lima: "tanto o Tute quanto o China, especialmente o China, tocava um estilo de violão chamado de "Violão Martelo", aquele violão cujas as notas, cuja as intervenções estão sempre apoiadas no tempo forte: tum, tum, tum, tum, tum, tum, tum ... fazer mais de três colcheias já era uma extravagância!”

André Tandeta: "a formação eles chamavam de Jazz Band, mesmo que não fosse para tocar jazz."

Flávio Silva: "mas você tem as fotos do grupo do Pixinguinha em Buenos Aires em 1925 que são de uma Big Band americana (na verdade uma small band).

Henrique Cazes: "na verdade o Pixinguinha vai se tornar realmente um arranjador a partir de quando ele volta de Paris, em 1922/23 e ele vai trabalhar no teatro de revista. E o Teatro de Revista vai ser o laboratório de instrumentação dele."

Wilson das Neves (lenda da bateria brasileira): "não tinha nem contrabaixo, a tuba que fazia o baixo!"

Henrique Cazes: "o Pixinguinha quando vai fazer as orquestrações ele vai usar muito desde o princípio a tuba. Inclusive, uma curiosidade, é que um dos tubistas que gravou com o Pixinguinha na década de 1930 foi o Eleazar de Carvalho (Iguatu 1912 - São Paulo 1996). Eleazar trabalhou bastante como Pixinguinha. Foram colegas, eles se conheciam da Escola de Música (hoje UFRJ), foram colegas em algumas disciplinas e o quando perguntavam a ele: Pixinguinha você se formou na Escola? Ele dizia: passei direitinho sim, mas quem estudava mesmo era o Eliazar!”

Omar Cavalheiro (contrabaixista e professor): "o baixo que o Pixinguinha escreveu para a tuba é uma grande referência pra gente tocar o baixo. A gente pode até enxugar algumas notas, alguns desenhos e tal, mas é a grande referência!”

André Tandeta: "a bateria como a gente conhece, o que em inglês chama se durm set, eu não sei quando chegou aqui no Brasil, mas... já tinha ouvido falar, alguma coisa na década de 1920.” 
Oscar “Bolão” (baterista e professor): “o Perrone se, eu não me engano, é de 1908, ele em 1920 já tocava. Tocava em leiteria, em cinema, em... o Perrone (Luciano Perrone 1908 - 2001) é do tempo que não tinha bateria ainda, ele me contou algumas coisas: eles colocavam a caixa no espaldar de uma cadeira, não havia estante de caixa. Era uma coisa bem pré histórica mesmo! Ele dizia que aí quando chegou o bumbo esse não tinha pedal, ele falava que às vezes até chutava o bumbo, o Perrone é dessa época. Tem uns caras que são contemporâneos dele: um cara que eu acho um baterista maravilhoso que chama se Valfrido Silva, de Niterói, que é um suingueiro danado, um sambeiro danado! Dessa Geração do Perrone tem o SUT...”

Dazinho (lenda da bateria brasileira): “... SUT, Sut velho. Tem um filme antigo que orquestra tocava e ele fazendo malabarismos com a baqueta ..."

Wilson das Neves: "Sut, Sutinho..."

Oscar “Bolão”: “aí depois veio o Sutinho, enfim, eu não sei nos outros estados como é que era, o Sut era até paulista, ele veio morar no Rio, mas aqui no Rio de Janeiro a gente pode dizer que o Perrone de uma maneira geral pode ser considerado o pai da bateria brasileira, entende?”

Henrique Cazes: "é, a bateria já estava sendo usada. Inclusive o Luciano Perrone, com quem eu conversava muito sobre esses assuntos, falou que ele era um cara que toda vez que chegava um artista aqui com um músico de fora, um baterista, ele ia lá pra ver uma novidade, né? Porque a bateria que a gente está falando é um instrumento que tem um bumbo que é chutado, que não tem pedal... não é aquele drum set que você vai ter a partir dos anos 1930 e no Brasil a partir de 1940 praticamente."

Oscar "Bolão”: “a bateria antes eram três instrumentos, eram três caras que tocavam o bumbo, a caixa e o prato."

André Tandeta: "o cara tinha que fazer ali o que três ou quatro faziam, então foi adaptando."

Oscar "Bolão”: "a escovinha chegou aqui por volta de quase 1928/29 e antes rolava um ganzá que era uma coisa que eu fico imaginando... você pode imaginar o ganzá primitivo o barulho que aquele negócio fazia? Com pedra dentro! Eu ainda cheguei a pegar esses ganzás que tinham pedras dentro, um barulho insuportável!"

André Tandeta: "as linhas, né? As linhas que os caras tocavam nos diferentes instrumentos foram sendo adaptadas para a bateria, do grave para o agudo."

Oscar "Bolão": "tem gravações com um instrumento que se usava muito no começo: omelê (nome genérico de vários instrumentos de percussão africanos). Acontecia comigo que eu tenho uma gravação que tem um solo de omelê. Então eu percebi que o que eu achava ser uma caixa sem esteira era um omele que estava sendo tocado."

Henrique Cazes: "e o Luciano Perrone dizia que o que ele fez foi olhar a batucada dos caras $e$ transferir aquilo para a bateria. Ele não inventou o samba, ele parendeu com aqueles caras, só que 
ele conseguia fazer vários instrumentos ali. Ele fazia a caixa surda, prendia com a mão, e fazia um tamborim. E ele copiava o agogô, pendurou o agogô na bateria também... agora, o João da Baiana João Machado Guedes (Rio 1887 - 1974) - tem uma importância especial para o Luciano, e quando a gente ouve uma gravação do João da Baiana, ele tocando o pandeiro no samba, o pandeiro dele é assim: tum, chi, qui, tum, chi, qui, tum ... não tem um e dois! No pandeiro dele o um e o dois são iguais! O Luciano aprendeu, segundo o próprio, vendo aqueles caras tocar e como ele era um sujeito que tinha muita técnica, era um cara de um inteligência musical privilegiada, ele conseguia solucionar aquilo tecnicamente na bateria."

Wilson das Neves: "É um ritmo muito complicado pra se escrever! Ninguém toca do jeito que escreve!”

André "Boxexa” Santos: "se você pegar as partituras originais, na linha de bateria normalmente vem aquela célula do garfinho: tá, tá..tá, tá, tá..tá, tá, tá..tá, tá, tá..tá... duas vozes, uma que seria a caixa com o bumbo e alguns ataques de prato. Só quando a melodia tem alguma pontuação específica que: tá, tá..tá, TÁ...tá, tá..tá, tá... ou seja: não dá pra tocar ao pé da letra! Você tem que conhecer, então fui desesperado procurar o Bolão!”

Oscar "Bolão”: “não mostra tudo não! Porque esses caras chegam lá e fazem um método!"

Omar Cavalheiro: "ele falou: olha, você pode fazer qualquer coisa, agora, só não faz TUMTUM! Aí eu comecei a tomar consciência que o molho do samba fica muito mais legal!”

Oscar "Bolão": "e fica gostoso cara, sabe?"

Omar Cavalheiro: “duas semínimas, você acentua o segundo tempo e por ali você vai naquela economia ... tem outros fazendo essa função, de repente entra um repique, entra uma coisa, entra um pandeiro, então naquilo ali você fazer o TUMTUM dá uma congestionada às vezes!”

Luís Filipe de Lima: "essa é uma ótima questão: o que esperar do contrabaixista que toca com junto com o violão de sete cordas e do violão de sete cordas que toca junto com o baixista. Eu acho o seguinte: pra mim a questão é clara, é preciso que o baixista ouça o sete cordas e é preciso que o sete cordas ouça o baixista. Tocar em conjunto é ouvir."

No próximo capítulo falaremos de Radamés Gnattali.

Vamos ouvir como se tocava contrabaixo no começo das rádios e as histórias de seus heróis, contadas por eles mesmos, até lá! 


\section{RADAMÉS O INVENTOR DO FUTURO}

\subsection{INTRODUÇÃO}

O contrabaixista e compositor Paul McCartney em 1994 escreveu uma nota que ficou eternizada em sua biografia autorizada feita pelo fotógrafo Barry Miles": "Ifeel like the sixties is about to happen, It feels like a period in the future to me, rather than a period in the past" - "Eu sinto que os anos sessenta estão prestes a acontecer, parece um período no futuro para mim, em vez de um período no passado". Podemos dizer que o "futuro" da indústria fonográfica e dos gêneros que conhecemos hoje como música popular brasileira está nos anos de 1940, mais precisamente em 43, no programa "Um Milhão de Melodias"2, que acontecia no Rio de Janeiro, nos estúdios da Rádio Nacional, sob a direção do radialista mineiro José Mauro e arranjos do maestro Radamés Gnattali que entrou na rádio em 1936 vindo da concorrente Marink Veiga, numa estratégia de passar a ser a número um em audiência... Deu certo.

O programa ficou 13 anos no ar. Contava com os lendários: Luciano Perrone à bateria, Pedro Vidal Ramos ao contrabaixo, Aníbal Augusto Sardinha, o Garoto ao violão e também nesse instrumento Bola Sete e mais tarde Zé Meneses, na percussão: João da Baiana e Heitor dos Prazeres e o próprio Radamés ao piano.

Mas para tentar explicar o fenômeno Radamés e sua inovadora maneira de escrever para grupos regionais temos que entender sua trajetória. Gaúcho, nascido em 1906 em Porto Alegre, filho dos imigrantes italianos Adélia Fossati Gnattali, professora de piano, e Alessandro Gnattali, contrabaixista, fagotista e maestro. Teve a sorte de vir a ser estudante de um dos fundadores da maioria das escolas de música no sudeste e sul do Brasil, o maestro Guilherme Fontainha. Fontainha entre 1904 e 1914 estudou em Berlin e Paris onde foi discípulo de um dos últimos alunos de Franz Liszt, o pianista Conrad Ausorg e depois foi pupilo de Michael von Zadora, discípulo de Busoni. Fontainha trouxe Radamés pela primeira vez ao Rio em 1923 e depois novamente no fim da década de 20, desta vez para ficar e tentar um concurso para professor no antigo Instituto Nacional de Música hoje Escola de Música da UFRJ. Veio então a revolução de $30 \ldots$

André Cardoso 3 (maestro e professor): "a revolução de 30 foi um marco divisório na carreira dele, que ele esperava poder ingresar no Instituto Nacional de Música como professor através de concurso e que a revolução de 30 adiou o concurso para o qual ele estava se preparando e ele por uma questão

\footnotetext{
${ }^{1}$ Barry Miles foi fotógrafo dos Beatles durante quase todo o período de ascensão do grupo e tornou se um dos maiores amigos do leader da banda e em 1196 escreveu sua versão da biografia de Paul McCartney.

${ }^{2}$ O repertório a ser apresentado em "Um Milhão de Melodias" era escolhido por Paulo Tapajós e Haroldo Barbosa, com direção de José Mauro.

${ }^{3}$ Entrevista colhida em 17 de agosto de 2016 no Theatro Municipal do Rio de Janeiro
} 
de necessidade acabou indo para a prática pianística em cinemas mudos, em cafés e nas rádios, primeiro na Marink Veiga e depois na Nacional. Onde ele construiu a carreira dele e se transformou no músico extraordinário que foi. Fundamental."

Luiz Alves" (contrabaixista): "A formação que a gente tinha era pelo rádio mais, a televisão começou depois e não tinha nada de música. Tinha a orquestra da Rádio Nacional com o Chiquinho do Acordeom, era a maior cultura da época e onde a gente aprendeu alguma coisa. Ah, o Radamés, é claro! O quinteto da Radamés que era a base das coisas."

Bijus - Moacyr Viana Marques da Silva (saxofonista): "Radamés era o maestro da Rádio Nacional, eu trabalhei com ele na Rádio, Tinha orquestra com cinco saxofones, tinha um conjunto regional, a Rádio Nacional tinha tudo!"

Flávio Silva" (musicólogo): "Há uma fronteira! Tanto que o grande desenvolvimento da rádio a grande popularização da rádio vai acontecer não na época que o cara pegava um bambu e esticava um fio e pegava a tal da rádio galena para ouvir rádio com uma chiadeira infernal, mas vai acontecer a partir do momento em que a rádio se eletrifica e que o disco se eletrifica, ao mesmo tempo."

Henrique Cazes ${ }^{7}$ (cavaquinista e professor): “a partir de 1936 o Radamés que era pianista na RCA Victor começa também a escrever os seus arranjos. E assim como o Pixinguinha teve a Carmen Miranda para fazer sucesso com a música "Tai" e espalhar o nome dele como arranjador o Radamés teve o Orlando Silva, o cantor das multidões, e o Radamés se transforma então, com uma característica muito diferente do Pixinguinha num orquestrador. Ele usava cordas e quando a gente fala cordas muitas vezes naquelas gravações dos anos 40 era um cello e dois violinos. Era uma coisa muito... os estúdios eram pequenos e as condições técnicas eram também pequenas, mas ele fazia aquilo com muito capricho, por exemplo a música "Lábios que Eu Beijei” que tem o solo de violoncelo da música popular no Brasil, cantada pelo Orlando Silva, como o Iberê Gomes Grosso no cello. São coisas marcantes que vão fazer o Radamés se destacar do Pixinguinha e eles distribuírem o repertório na gravadora, o Radamés cuidando da parte mais romântica e o Pixinguinha da parte mais carnavalesca, das marchinhas, etc."

Flávio Silva (musicólogo): “ eu ouvi uma vez o Humberto Franceschi, um tremendo colecionador de gravações, um cara muito mais radical que o Tinhorão em matéria de fidelidade às origens. Ele uma vez me mostrou uns arranjos do Radamés que eram imitação barata de coisas americanas. Mas era aquele negócio, o Radamés tinha fabricar instrumentação uma atrás da outra. De vez em quando ele

\footnotetext{
${ }^{4}$ Entrevista gravada em 18 de abril de 2016 em Copacabana, Rio de Janeiro

${ }^{5}$ Entrevista filmada em 13 de abril de 2016 no bairro do Grajaú, Rio de Janeiro

${ }^{6}$ Entrevista colhida em 27 de abril de 2016 em Copacabana, Rio de Janeiro Email enviado me por Flávio Silva, musicólogo, no Rio de Janeiro na tarde do dia 27 de dezembro de 2016

${ }^{7}$ Entrevista colhida em 29 de abril de 2016 no Jardim Botânico,, Rio de Janeiro
} 
tinha tempo e mais interesse pela música para fazer uma coisa melhor. Mas quando tinha que fazer qualquer coisa ele escrevia de qualquer jeito."

Luís Filipe de Lima ${ }^{8}$ (violonista e escritor): “ as frases de sete cordas que ele escrevia ... o violão de sete cordas é uma espécie de "baixo contínuo" do choro e do samba e tocada de uma maneira livre e improvisada e claro que tem seu espaço delimitado e uma linguagem delimitada assim como uma fraseologia delimitada, mas dentro de muito espaço. Pouquíssima gente escrevia frases para o set cordas, no máximo obrigações - o que se chama mais no vocabulário de guitarra elétrica de riffs. Mas fora isso era muito raro alguém escrever um arranjo com frases de ponta a ponta para o violão de sete cordas. Inclusive um musico que visse uma partitura pela frente iria "esbofetear" o arranjador. Agora, nesse contexto da Camerata Carioca, com arranjos que valorizavam nuances e cada instrumento solava, o cavaquinho era capaz de solar determinados trechos e também fazer contracantos não apenas acompanhamentos e os violões ídem naquela formação. Então o Radamés começou a escrever frases que também não tinham muito a cara do violão de sete cordas tradicional, já tinham outros elementos, harmonizações que não eram comuns ao choro tradicional e algumas frases com sentido claramente pianísticas. Claro. Não foi à toa, o Radamés sabia plenamente o que estava fazendo."

Omar Cavalheiro" (contrabaixista e professor): "O Radamés às vezes fazia a parte inteira, no "Bate Papo a Três Vozes" ele fez tudo! Se você olhar a partitura ela é preta de notas, a partitura original que o contrabaixista Pedro Vidal Ramos tocou. Eu fiz uma ou outra modificação quando a gente regravou com o Novo Quinteto, mas tinha muito hora cifra, hora a linha de contrabaixo escrita (notação), então ele também dava liberdade, ele tinha uma característica que o que o músico fizesse em cima do que ele escreveu ele dava "carta branca”, ele aprovava! Ele costumava a dizer assim: “ poxa, eu escrevi o arranjo, mas quem está tocando é você! É o contrabaixo! Faça isso!”

Wilson Das Neves ${ }^{10}$ (lenda da bateria): "por exemplo, não tinha cifra! Quando eu comecei a gravar na década de cinquenta não tinha cifra. Era nota, o piano tocava aqueles cachos de nota e o violão também, não tinha cifra! Aí com o advento da Bossa-Nova veio o negócio de cifra. O cara colocava décima terceira, vigésima não sei o que, uma coisa mais moderna, mas a diferença taí, pra mim o ritmo é o samba.

Zeca Assumpção" ${ }^{11}$ (contrabaixista e um dos membros da banda de Radamés): "Não, Radamés já escrevia cifra!"

\footnotetext{
${ }^{8}$ Entrevista filmada em 12 de dezembro de 2016 no Jardim Botânico, Rio de Janeiro

${ }^{9}$ Entrevista filmada em 05 de outubro de 2016 no Jardim Botânico, Rio de Janeiro

${ }^{10}$ Entrevista gravada na tarde do dia 14 de agosto de 2016 no bairro do Jardim Guanabara, Rio de Janeiro

${ }^{11}$ Entrevista filmada em dois de outubro de 2016 no Jardim Botânico, Rio de Janeiro
} 
Henrique Cazes: "O guitarrista Zé Menezes contou me uma coisa, que em 1945 quando ele chega ao RIo de Janeiro ele ouviu dizer que tinha um cara que ensinava cifra, ensinava a escrever e ler cifra. Era uma novidade que estava chegando. E era um cara que na verdade não era músico, ele um copista de uma editora, mas tinha passado um tempo nos Estados Unidos e lá ele tinha prendido aquilo. Eu acredito que por um momento no começo dos anos quarenta essa cifra apareceu, que foi uma simplificação que melhorou muito a vida das pessoas que escreviam muito. O Radamés dizia: "quando ficava apertado de tempo eu colocava uma cifra e escrevia SOLO DE PIANO, chegava na hora fazia", não dava tempo de fazer o arranjo."

Luiz Alves (contrabaixista): "Mas cifra mesmo eu comecei estudar independente (autodidata), mais tocando mesmo. Em gravações com o Wagner Tyso (pianista), nós começamos a tocar juntos, na época a gente era novo, e fomos tocando em várias formações e eu fui pegando as coisas assim."

Henrique Cazes: "O Radamés vai usar contrabaixo muito cedo, inclusive ele tem aquela peça dedicada ao pai dele: "Canção e Dança”, era uma peça dos tempos da juventude dedicada ao pai. Uma peça que já foi tocada, eu mesmo vi o Sandrino (Santoro) tocando isso."

Sandrino Santoro" 12 (contrabaixista e professor): "O Vidal (Pedro Vidal Ramos), que foi um grande amigo meu, e tocamos juntos na Sinfônica Nacional um do lado do outro, uma faz ele foi spalla depois eu, foi assim uma coisa maravilhosa!”

Sérgio Barrozo" ${ }^{13}$ (contrabaixista): "Os baixista que eu me lembro que cruzava em estúdio eram o Vidal (Pedro Vidal Ramos), que era o mais velho de todos..."

Dazinho - Gildásio Paiva ${ }^{14}$ (baterista): "O Vidal tinha a mania de falar difícil!"

Sandrino Santoro: "Ele foi aluno do Uruguai (Rodolfo) Battesine. A gente se dava muito bem.

André Tandeta" (baterista e professor): "O Vidal era do conjunto do Radamés e os músicos "das antigas" tem muitas estórias com o Vidal, algumas bem engraçadas."

Oscar "Bolão” Pelon" (baterista): "Eu não sei, mas acho que é coisa dos anos quarenta, o grupo era: Vidal (contrabaixo), Chiquinho do Acordeom (no acordeom), antes de Zé menezes (guitarra) era o Garoto, Luciano Perrone (bateria) e Radamés (piano).

Henrique Cazes: "um exemplo que a gente pode buscar de uma orquestração de orquestração no padrão como é hoje em dia é a gravação original da música "Copacabana” (1946 de Braguinha e Alberto Ribeiro lançada pela Continental) com Dick Farney cantando e cordas, um arranjo muito bonito, harmonia linda, e tá lá o contrabaixo e o contrabaixo é o Vidal, Pedro Vidal Ramos, que era

\footnotetext{
${ }^{12}$ Entrevista filmada em sete de abril de 2016 no bairro do Flamengo, Rio de Janeiro

${ }^{13}$ Entrevista filmada em nove de abril de 2016 no bairro da Lagoa, Rio de Janeiro

${ }^{14}$ Entrevista filmada em 31 de outubro de 2016 no bairro da Tijuca, Rio de Janeiro

${ }^{15}$ Entrevista filmada em 13 de junho de 2016 no Jardim Botânico, Rio de Janeiro

${ }^{16}$ Entrevista filmada em 11 de junho de 2016 no Jardim Botânico, Rio de Janeiro
} 
companheiro do Radamés já lá na Rádio Nacional, antes certamente já teriam tocado em alguns lugares e tinha uma coisa o Luciano Perrone conhece o Radamés em 1929 e vão trabalhar juntos de 1929 até 1986 quando o Radamés fica doente."

André Tandeta: "é que eles dois se conheceram, Radamés e o PErrone, em Poços de Cladas - MG tocando num casino.

Wilson Das Neves: “ele era um solista, baterista solista. Tem uns que são e outros não. Eu por exemplo nunca me preocupei em solar, eu solva quatro compassos, oito no máximo e já tava achando muito, porque meu negócio era acompanhar eu gostava de colocar a orquestra do meu jeito.

Zeca Assumpção: "Eu tive que me adaptar não só a esse samba mas a maneira de tocar dentro do grupo do Radamés que tinha a maneira de tocar do Perrone, ele (Perrone) fazia as melodias nos tons. Eu conheci o Radamés através do Sergio Saraceni, que era um músico compositor da Globo etc. Eles eram amigos, ele o Radamés e o Didier Luita (Aluisio Didier), e eu fiquei amigo do Radamés, mas não de tocar, mas de ir em bar para tomar chopp e o Radamés estava remontando o quinteto dele. Eu tocava na boate People nessa época e um dia eles apareceram de noite lá, o Radamés e o Sérgio, eles ficaram ouvindo eu tocar e tudo mais. No dia seguinte fui encontrar com eles novamente para tomar um chopp e ele falou: "Zeca, você não quer tocar no meu conjunto que nós estamos remontando o quinteto? Eu gostaria que você tocasse comigo”. Eu falei: Radamés eu não tocar com vocês porque eu não sei tocar sua música, vocês tocam um choro que eu nunca toquei na verdade! Eu acho difícil pra mim! E ele falou: “Então você vai aprender”. Depois disso eu fui obrigado a tocar com ele, fui morrendo de medo porque eu sabia que era difícil, mas ele e todos os demias do grupo foram muito pacientes comigo, tiveram a paciÊncia de eu aprender e estudar, ensaiar e repete aqui e repete ali e tal. Eu toquei, foi um prazer enorme tocar com o Radamés e o grupo original e estava fazendo o lugar do Vidal.

Henrique Cazes: "a verdade é que quando inaugura a Rádio Nacional em 1936 o Radamés já tem esse trio de bas, piano, baixo e bateria e vai tocar com essa formação em tudo. As gravações todas até o final dos anos 50... o final dos anos 50 tem um ponto fora da curva que é disco "Paulo Moura Interpreta Radamés", que é um outro contrabaixista que é uma coisa um pouco da época, aquela época já querendo ser meio Bossa-Nova." 


\section{REFERÊNCIA}

Entrevistas coisas no Rio de janeiro em 2015 e 2016 